\title{
Comparative Analyses of the Inhibitive Influence of Cascabela thevetia and Jatropha curcas Leaves Extracts on Mild Steel
}

\author{
A. S. Adekunle*, A. A. Adeleke*, P. P. Ikubanni **† and O. A. Adewuyi* \\ *Department of Mechanical Engineering, University of Ilorin, Nigeria \\ **Department of Mechanical Engineering, Landmark University, Omu-Aran, Nigeria \\ $†$ Corresponding author: P. P. Ikubanni; ikubanni.peter@lmu.edu.ng
}

Nat. Env. \& Poll. Tech.

Website: www.neptjournal.com

Received: 10-09-2019

Revised: 14-10-2019

Accepted: 07-11-2019

Key Words:

Mild steel

Cascabela thevetia

Jatropha curcas

Corrosion inhibitor

Inhibition efficiency

\begin{abstract}
The inhibitive properties of the extracts of Cascabela thevetia and Jatropha curcas were comparatively studied on corrosion of mild steel in $\mathrm{H}_{2} \mathrm{SO}_{4}$ acid. The extracts of both plants contained active phytochemical constituents such as tannins, saponins, alkaloids, flavonoids, terpenes and phenols which made them useful as good corrosion inhibitors. The extract concentrations were varied from 0.3 to $1.5 \mathrm{~g} / \mathrm{L}$ during both the gravimetric and gasometric analyses for an exposure time of 7-28 days. The weight loss of the coupon, corrosion rate, surface coverage and inhibitive efficiency was evaluated for both the extracts. The results of the gravimetric and gasometric analyses indicated that inhibitive efficiency increased with an increase in the concentration of inhibitors and the highest was $55.77 \%$ for Jatrophas curcas at the concentration of $1.5 \mathrm{~g} / \mathrm{L}$. The weight loss was a little lower for Cascabela thevetia (4.36 g) compared to Jatrophas curcas $(4.66 \mathrm{~g})$ at the highest exposure time used (28 days). Cascabela thevetia has a better surface coverage (0.68) than Jatropha curcas (0.61), hence, Cascabela thevetia inhibits better for a 7-day exposure time. However, when the mild steel was further exposed for more than 7 days, Jatropha curcas exhibited a better inhibitive property. The highest and least hydrogen gas evolution was obtained at $0.3 \mathrm{~g} / \mathrm{L}$ concentration ( 7 minutes) and $1.5 \mathrm{~g} / \mathrm{L}$ concentration (1 minute) for both Cascabela thevetia and Jatropha curcas leaves extracts, respectively. Based on the results, the utilization of extracts of Cascabela thevetia and Jatropha curcas leaves as replacements for toxic organic inhibitors in industries are recommended.
\end{abstract}

\section{INTRODUCTION}

The deterioration of materials as a result of its reaction with the environment is termed corrosion. It is a natural phenomenon that results in the destructive attack of any metal through chemical or electrochemical reaction with the environment (Bradford 1993, Perez 2004). It is described as the propensity of metallic materials to return to its organic state in a steadier mineral form (Mshelia et al. 2017). Apart from gold and platinum, nearly all metals will disintegrate in the environment that is oxidized thereby leading to the formation of compounds either in their oxides, sulphides or hydroxides state. Although metals tend to corrode naturally, the environment that metal is exposed to has great strength on the speed at which it will disintegrate (Syed 2006).

Corrosion is said to be a societal menace that causes numerous damages, destruction and degradation especially in industries as well as in automobiles, aeroplanes, highway bridges, household gadgets and many more (Odusote \& Ajayi 2013). Corrosion is a constant and continuous problem which cannot be eliminated. Prevention is one of the best methods to combat corrosion. Therefore, engineering materials are required to be protected against corrosion. One of such engineering materials is the mild steel which has found usefulness in automobile, construction, petrochemical industries and many more. It is a choice material due to its availability, low cost and excellent mechanical properties (Al-Otaibi et al. 2012). These materials are very susceptible to corrode in harsh and hostile aggressive environment. To mitigate the effect of corrosion on metal, the metallic corrosion rate can be avoided, prevented or lowered with the addition of corrosion inhibitor, which is one of the best-known methods of corrosion protection that is mostly used in the industry (Al-Otaibi et al. 2012).

Corrosion inhibitors are materials or substances which are introduced into a corrosion system in a little amount to lower or avert the metal reaction of the corrosive media (Singh et al. 2012). Various methods that have been used to control corrosion include coatings, inhibitors, designs, material selection and cathodic protection. However, inhibitors utilization has been one of the most practicable technique for corrosion protection in harsh environment (Ansari et al. 
2012). Fundamentally, the various forms of corrosion inhibitors include anodic, cathodic, mixed and volatile corrosion inhibitors (Taghavikish et al. 2017, Asmara et al. 2017). Moreover, synthetic (organic), metallic (inorganic) and green inhibitors (natural products) are the variously classified corrosion inhibitors (Ajayi et al. 2012, Rani \& Basu 2012). Researches have revealed that the toxicity of some of the synthetic and inorganic inhibitors is instigating mutation of genes as well as the failure of kidney and liver, to mention but a few (Singh et al. 2012). Green corrosion inhibitors have been prompted due to the environmental toxicity of organic corrosion inhibitors (Rani \& Basu 2012). The advantages of green corrosion inhibitors over organic inhibitors are their biodegradability, environmental friendliness, ecological acceptance and they do not possess heavy metal or other toxic compounds. They are also not expensive, readily available and renewable (Odusote \& Ajayi 2013, Rani \& Basu 2012).

Green corrosion inhibitors have been seen to be effective in reducing the rate of corrosion of metals that are exposed to a hostile environment. Various studies have reported that these inhibitors (extract from leaves, barks, seeds, roots, and so on) have good inhibition efficiencies both in acidic and other aggressive media (Odusote \& Ajayi 2013, Umoren et al. 2006). Corrosion inhibiting abilities of these green inhibitors have been attributed to the existence of organic compounds. These compounds are mainly tannins, saponins, alkaloids, steroids, flavonoids, amino acids, etc. in the plants (Rani \& Basu 2012, Martinez 2003, Chowdhary et al. 2004, El-Etre et al. 2005). More so, numerous extracts from different parts of plants have been examined as metal corrosion inhibitors and have been reported to have inhibitive effects through the formation of a passivating layer (protective film) on the surface of the metal by adsorption of phytochemical molecules that are present in the plants on the surface of the metal (Oguzie \& Ebenso 2006, El-Etre \& El-Tantawy 2006). The plant parts, as well as their location, is a great determinant in the compound yields and the corrosion inhibitor abilities (Okafor et al. 2008). A few of plants extracts are Delonix regia extract (Abiola et al. 2007), natural onion juice (El-Etre 2006), Carica papaya leaf extract (Oki et al. 2015), Punica granatum extract (Rani \& Selvaraj 2010), Hibiscus sabdariffa extract (Oguzie 2008), Rhizophora racemose extract (Oki et al. 2011), Azadirachta indica extract (Okafor et al. 2010), Lawsonia extract (El-Etre et al. 2005) and others.

Based on the current focus on green inhibitors, this study aims at exploring the utilization of plant extracts as green corrosion inhibitors for metallic materials. The study investigates the corrosion inhibitive properties of Cascabela thevetia and Jatropha carcus leaves extracts on mild steel corrosion by employing gravimetric and gasometric methods. Furthermore, comparison of the inhibitive effects was made between these two green inhibitors to ascertain the one which has higher inhibitive properties.

\section{MATERIALS AND METHODS}

Materials and equipment: The materials used for the experiment were mild steel (coupon) with its composition given in Table 1, sulphuric acid $\left(\mathrm{H}_{2} \mathrm{SO}_{4}\right)$ solution, Cascabela thevetia leaves, Jatropha curcas leaves, methanol, ethanol and acetone.

A mild steel rectangular specimen was mechanically cut into coupons of $35 \times 20 \times 1 \mathrm{~mm}$ with a $3 \mathrm{~mm}$ hole drilled in each of the coupons for suspension purpose. The exposed area of each coupon was mechanically abraded with emery paper of different grades, polished and degreased in ethanol, cleaned with acetone and then kept inside the desiccator.

Preparation of the inhibitors (Cascabela thevetia and Jatropha curcas leaf extracts): The leaves were plucked from a farm in Ilorin, Nigeria and washed and sliced into pieces. The sliced leaves were dried at room temperature and pulverized into powdery form. The pulverized form of the leaves was soaked with methanol for 48 hours. To obtain the needed extract, solution filtration was carried out while methanol was evaporated from the filtrate. A digital electronic weighing balance was used to weigh the extract. Fig. 1(a \& b) show how the extracts were filtered while Fig. 1c represents the experimental set up for gasometric analysis.

Cascabela thevetia and Jatropha curcas leaves phytochemical analysis: The phytochemical analysis of both the leaves disclosed the existence of tannins, saponins, flavonoids, alkaloids, phenol and terpenoids. It has been reported that the most active green inhibitor constituents in plants are tannins, saponins and alkaloids (Rani \& Basu 2012, Martinez 2003, Chowdhary et al. 2004, El-Etre et al. 2005).

Key: + means present, - means absent

Gravimetric analysis: Extract ranging from 0.3 to $1.5 \mathrm{~g}$ were dissolved in separate beakers that contain 1 litre of sulphuric acid solution each, as the inhibited environments. The pre-treated coupons were removed from the desiccator. The weights of these coupons $\left(w_{1}\right)$ were determined using a

Table 1: Compositional analysis of mild steel sample.

\begin{tabular}{|lllllllllll}
\hline Element & $\mathrm{C}$ & $\mathrm{Si}$ & $\mathrm{Mn}$ & $\mathrm{P}$ & $\mathrm{S}$ & $\mathrm{Cr}$ & $\mathrm{Ni}$ & $\mathrm{Mo}$ & $\mathrm{Fe}$ \\
\hline Composition (\%wt.) & 0.242 & 0.119 & 0.304 & 0.012 & 0.007 & 0.175 & 0.154 & 0.094 & 98.7 \\
\hline
\end{tabular}



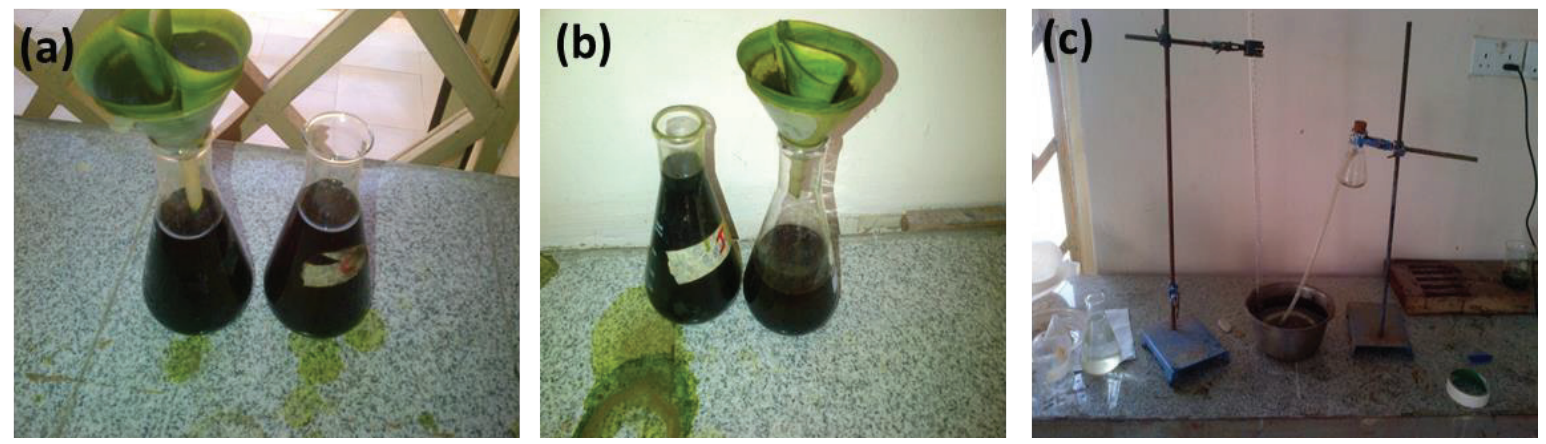

Fig. 1: (a) Filtration of Cascabela thevetia extract, (b) Filtration of Jatropha curcas extract, (c) Apparatus setup for gasometric analysis

digital electronic weighing balance of $\pm 0.01 \mathrm{~g}$ accuracy and the corresponding weight $\left(w_{l}\right)$ was recorded. The prepared coupons were suspended into the prepared environment. The coupons were taken away from the different environments (either uninhibited or inhibited environments) at the end of 7 days. The coupons were then removed and rinsed with ethanol and with acetone at the end of each interval. The coupon samples were weighed again and the obtained weights $\left(w_{2}\right)$ noted for each coupon. The experimentation for the study was carried out for 14, 21 and 28 days.

To obtain the weight loss for both the uninhibited and inhibited samples for each immersion period and the concentration of the inhibitors, Eq. (1) was used. Equations (2-4) were utilized to determine the corrosion rate, surface coverage and inhibitive efficiency of each inhibitor concentration (Ebenso et al. 2008, Eddy 2009):

$$
\Delta w=w_{1}-w_{2}
$$

Where, $\Delta w=$ weight loss, $w_{1}=$ initial coupon weight before immersion $(\mathrm{g})$ and $w_{2}=$ final coupon weight after immersion $(\mathrm{g})$.

$$
\text { Corrosion Rate }(C R)=\frac{\Delta W}{A T}
$$

Where, $A=$ Coupon area $\left(\mathrm{mm}^{2}\right)$ and $T=$ Time spent in both media (h).

$$
\text { Surface Coverage }(\theta)=\frac{\left(C R_{1}-C R_{2}\right)}{C R_{1}}
$$

Inhibitive Efficiency (I. E. $)=\theta \times 100 \%$

Where, $C R_{1}=$ Uninhibited environment corrosion rate and $C R_{2}=$ Inhibited environment corrosion rate, at the same interval.

Gasometric analysis: This experiment was carried out using $15 \times 10 \times 1 \mathrm{~mm}$ mild steel coupons. With regards to the evolution of gas at the interphase of corrosion, the gasometric (gas-volumetric) method offers a quick and dependable way of determining any perturbation by the inhibitor. Each coupon was released into the Buckner flask which contains $4 \mathrm{M} \mathrm{H}_{2} \mathrm{SO}_{4}$ solutions in the presence of both leaves' inhibition extracts at various concentrations $(0.3-1.5 \mathrm{~g} / \mathrm{L})$ as well as the blank one at room temperature. The initial hydrogen gas volume was recorded as $v_{1}$. The experimental arrangement was permitted to stay for seven minutes and hydrogen gas volume evolved was recorded per minute interval as $v_{2}$. The gasometric experiment was done within 24 hours.

Equations (5-8) were used to determine the volume change $(\Delta v)$, gas evolution rate $\left(R V_{H}\right)$, surface coverage $(\theta)$ and inhibitive efficiencies (I.E \%).

$$
\Delta v=v_{1}-v_{2}
$$

Where, $v_{1}=$ initial hydrogen gas volume and $v_{2}=$ final hydrogen gas volume

$$
\text { Rate of gas evolved }\left(R V_{H}\right)=\frac{\Delta V}{A T}
$$

Where, $A=$ Area of the coupon $\left(\mathrm{mm}^{2}\right)$ and $T=$ Time spent in both media ( $\mathrm{min})$

$$
\begin{aligned}
& \text { Surface Coverage }(\theta)=\frac{\left(R V_{1}-R V_{2}\right)}{R V_{1}} \\
& \text { Inhibitive Efficiency (I. E. })=\theta \times 100 \%
\end{aligned}
$$

Where, $R V_{1}=$ initial rate of gas evolved and $R V_{2}=$ final rate of gas evolved

\section{RESULTS AND DISCUSSION}

Gravimetric studies: Figs. 2 and 3 show the obtained results from the weight loss, corrosion rate and inhibitive efficiency of Cascabela thevetia and Jatropha curcas inhibitors at the varied concentrations of the inhibitor with exposure time, respectively for the coupons suspended in $\mathrm{H}_{2} \mathrm{SO}_{4}$.

With the use of Cascabela thevetia and Jatropha curcas, the weight loss increases with time of exposure for both the uninhibited (blank) and inhibited environments (Figs. 2 \& 
3). It was also discovered that in both cases, as the concentrations of the inhibitors increase, the weight loss reduce. In both cases, it was observed that a very high amount of weight was lost for the blank (un-inhibited) samples when compared with the inhibited samples between day 7 and day 14 when subjected into $\mathrm{H}_{2} \mathrm{SO}_{4}$ environment. This implies that uninhibited steel will easily corrode when exposed to a corrosive environment. The weight loss at day 14 for the blank sample in $\mathrm{H}_{2} \mathrm{SO}_{4}$ environment was $5.18 \mathrm{~g}$. However, within 21 days, the weight losses were observed to increase for both inhibitors in the inhibited environment. For the inhibited samples at various concentrations of Cascabela thevetia, same weight loss patterns were observed as the days increase from 7 to 21 days. However, between days 21 and 28 , the weight loss increases for $0.3 \mathrm{~g} / \mathrm{L}$ concentration between 5.43 and $5.88 \mathrm{~g} / \mathrm{L}$ while for other concentrations, the weight losses reduce (Fig. 2). Moreover, from Fig. 3, the weight losses of the inhibited samples follow the same

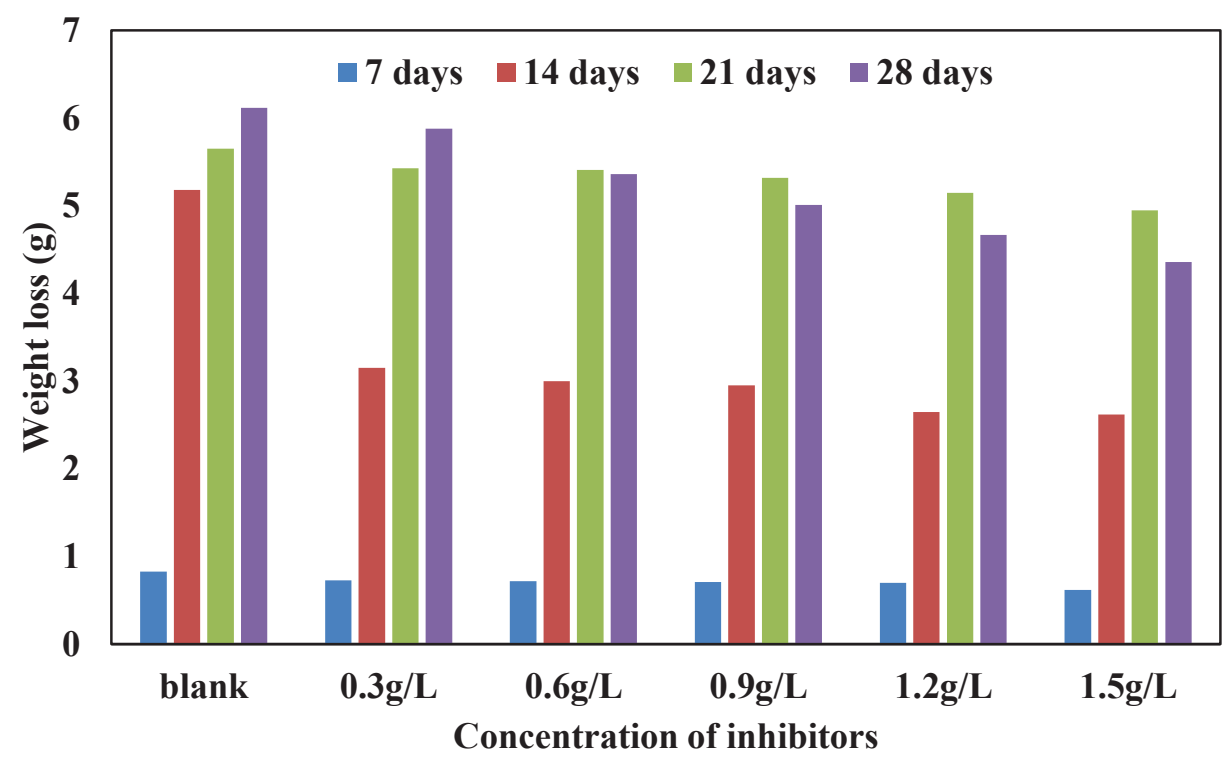

Fig. 2: Weight loss of mild steel in $\mathrm{H}_{2} \mathrm{SO}_{4}$ with different concentration of Cascabela thevetia inhibitor.

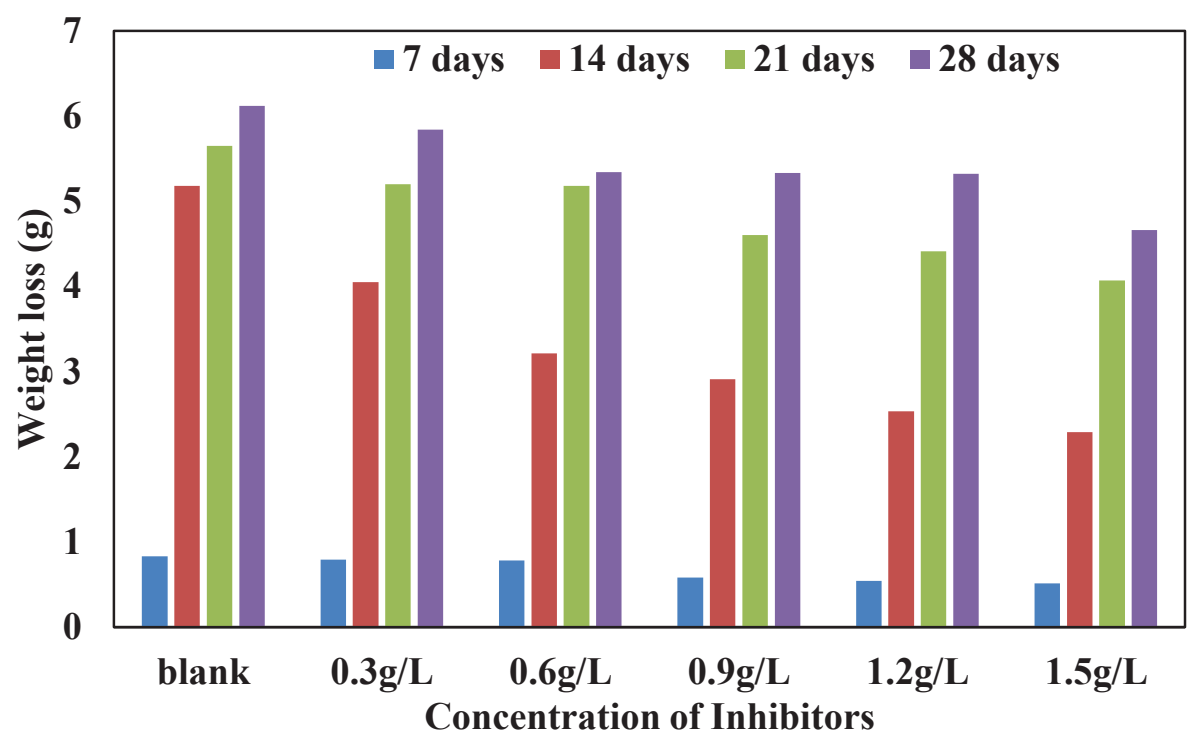

Fig. 3: Weight loss of mild steel in $\mathrm{H}_{2} \mathrm{SO}_{4}$ with different concentration of Jatropha curcas inhibitor. 
pattern at 0.6, 0.9, 1.2 and $1.5 \mathrm{~g} / \mathrm{L}$ concentrations of Jatropha curcas between days 7 and 21 . Only at $0.6 \mathrm{~g} / \mathrm{L}$ concentration of Jatropha curcas was the weight loss slightly increased while other concentrations show distinct weight losses between 21 and 28 days.

The weight loss reduction can be attributed to shielding film layer formation on the mild steel surface in the inhibited system (Oguzie \& Ebenso 2006, El-Etre \& El-Tamtawy 2006). The weight loss of the coupon in both inhibitors indicates that within 7-14 days at high concentration of 0.9-
$1.5 \mathrm{~g} / \mathrm{L}$, Cascabela thevetia proves to be a superior inhibitor when compared to Jatropha curcas. However, Jatropha curcas displays the minimum weight loss within 14-21 days regardless of the inhibitor concentration. Therefore, Jatropha curcas demonstrates to be a superior inhibitor within 21 to 28 days than Cascabela thevetia.

Additionally, the rate of corrosion for the blank sample increases and reaches a peak at day 14. A declining nature in the corrosion rate was observed between 14 and 28 days (Figs. 4 \& 5). The Cascabela thevetia has the highest cor-

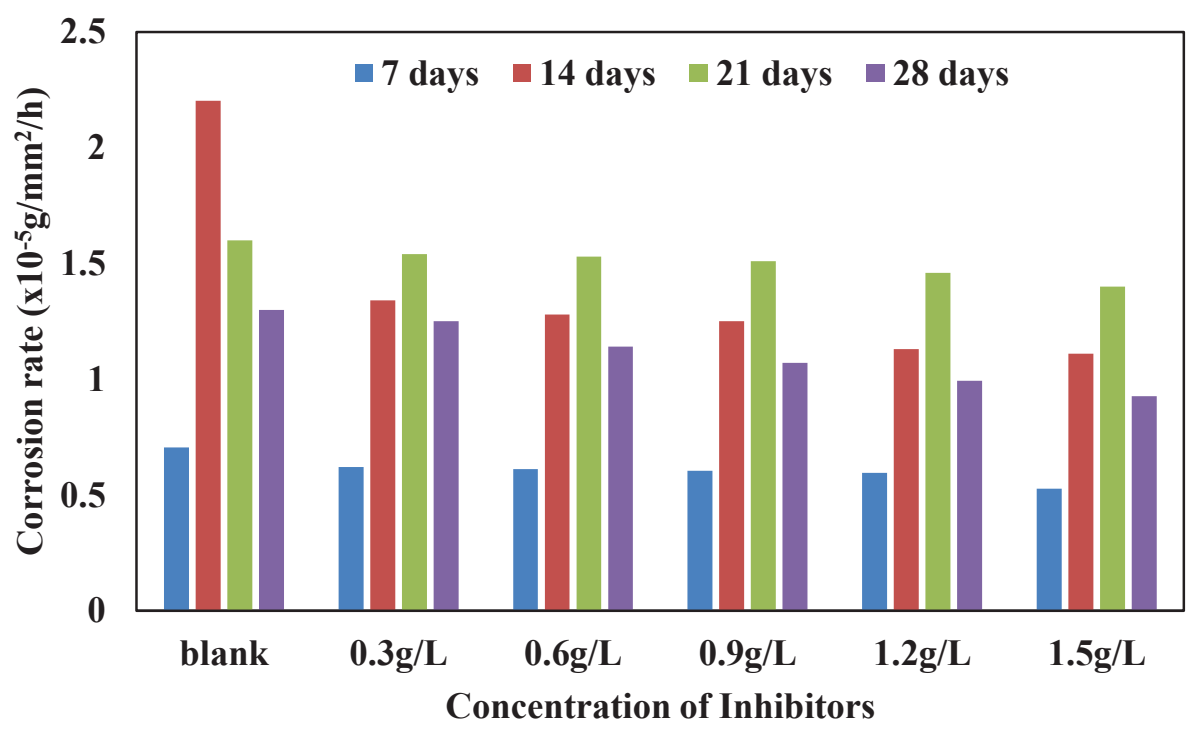

Fig. 4: Corrosion rate of mild steel in $\mathrm{H}_{2} \mathrm{SO}_{4}$ with varied concentrations of Cascabela thevetia inhibitor.

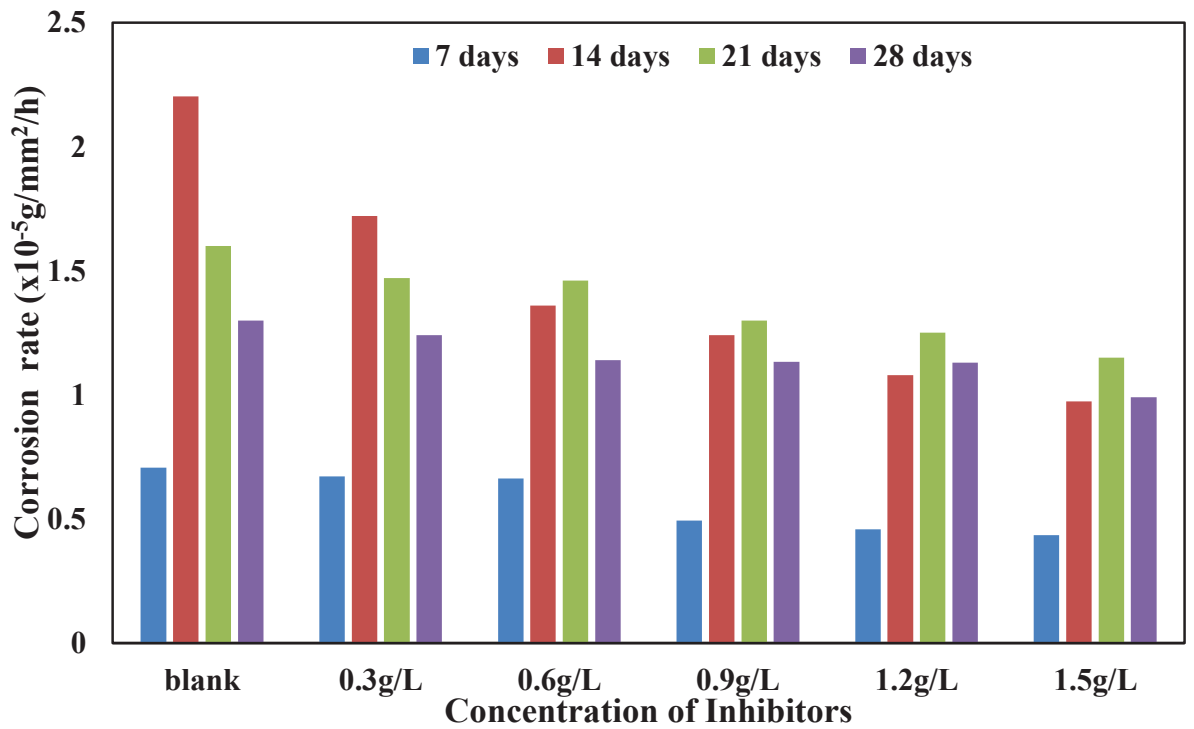

Fig. 5: Corrosion rate of mild steel in $\mathrm{H}_{2} \mathrm{SO}_{4}$ with varied concentrations of Jatropha curcas inhibitor. 
rosion rate of $1.54 \times 10^{-5} \mathrm{~g} / \mathrm{mm}^{2} / \mathrm{h}$ (in $0.3 \mathrm{~g} / \mathrm{L}$ ) and $1.4 \times$ $10^{-5} \mathrm{~g} / \mathrm{mm}^{2} / \mathrm{h}$ (in $1.5 \mathrm{~g} / \mathrm{L}$ ) as the least. However, Jatropha curcas has the highest corrosion rate of $1.72 \times 10^{-5} \mathrm{~g} / \mathrm{mm}^{2} / \mathrm{h}$ (in $0.3 \mathrm{~g} / \mathrm{L}$ ) and the least to be $0.974 \times 10^{-5} \mathrm{~g} / \mathrm{mm}^{2} / \mathrm{h}$ (in $1.5 / \mathrm{L})$. Generally, for both corrosion inhibitors at different concentrations, the rate of corrosion without regards to the level of inhibitor concentration is lower than the blank. From Fig. 4, it was observed that as the exposure time increases from days 7 to 21 , the corrosion rates increase for all the inhibited samples at various concentrations of Cascabela thevetia while the corrosion rates decline from days 21 to 28 . At $0.3 \mathrm{~g} / \mathrm{L}$ concentration of Jatropha curcas, the corrosion rate increases between days 7 and 14 where a peak was reached and declined until the end of day 28. However, other concentrations of Jatropha curcas increase from days 7 to 21 and a slight decline was observed until day 2 (Fig. 5). It can be said that the higher the concentration of the inhibitors in the environment, the lower the corrosion rate. This implies that the extracts from the leaves are good enough to protect or reduce the steel materials from corrosion. Higher concentrations of the extracts lower the rate of disintegration for a long time.

The decline in the rate of corrosion when the coupons are in the inhibited environments could be as a result of the inhibitor concentration increment which invariably suggests the adsorption of organic compounds present in the leaf extracts which could have formed the passive protecting film layer that has lowered the penetrability of the sulphuric acid onto the surface of the coupons mild steel. The corrosion rates could mean that the inhibitive effect of the inhibitor does not affect regardless of the inhibitor concentration after 21 and 14 days for Cascabela thevetia and Jatropha curcas, respectively. This might be as a result of the suspension of $\mathrm{H}_{2} \mathrm{SO}_{4}$ into $\mathrm{H}_{2}$ gas and $\mathrm{SO}_{4}{ }^{2-}$, that is, the $\mathrm{H}_{2}$ gas evolving and the media becomes less corrosive since $\mathrm{SO}_{4}$ is a base. Thus, Jatropha curcas is more effective as a corrosion inhibitor than Cascabela thevetia due to the number of days obtained from the experiment.

Figs. 6 and 7 show the inhibitors' inhibitive efficiency on mild steel coupon at different concentrations in $\mathrm{H}_{2} \mathrm{SO}_{4}$. The results show that for both Cascabela thevetia and Jatropha curcas inhibitors during the initial 14 days, the inhibitor concentration is proportional to the inhibitive efficiency, that is, increase in the inhibitor concentration is an increase in the inhibitive efficiency in an acidic environment. Considering Figs. 6 and 7, the highest inhibitive efficiencies of the Cascabela thevetia and Jatropha curcas inhibitors at 1.5 $\mathrm{g} / \mathrm{L}$ were obtained to be $49.6 \%$ and $55.8 \%$, respectively. At the same concentration, it can be said that Jatropha curcas gives better inhibitive efficiency than Cascabela thevetia. The maximum inhibitive efficiencies obtained at $1.5 \mathrm{~g} / \mathrm{L}$ concentration of the inhibitors in $\mathrm{H}_{2} \mathrm{SO}_{4}$ environment could be as a result of increased thickness of the shielding film layer formation which could be attributed to increase in the

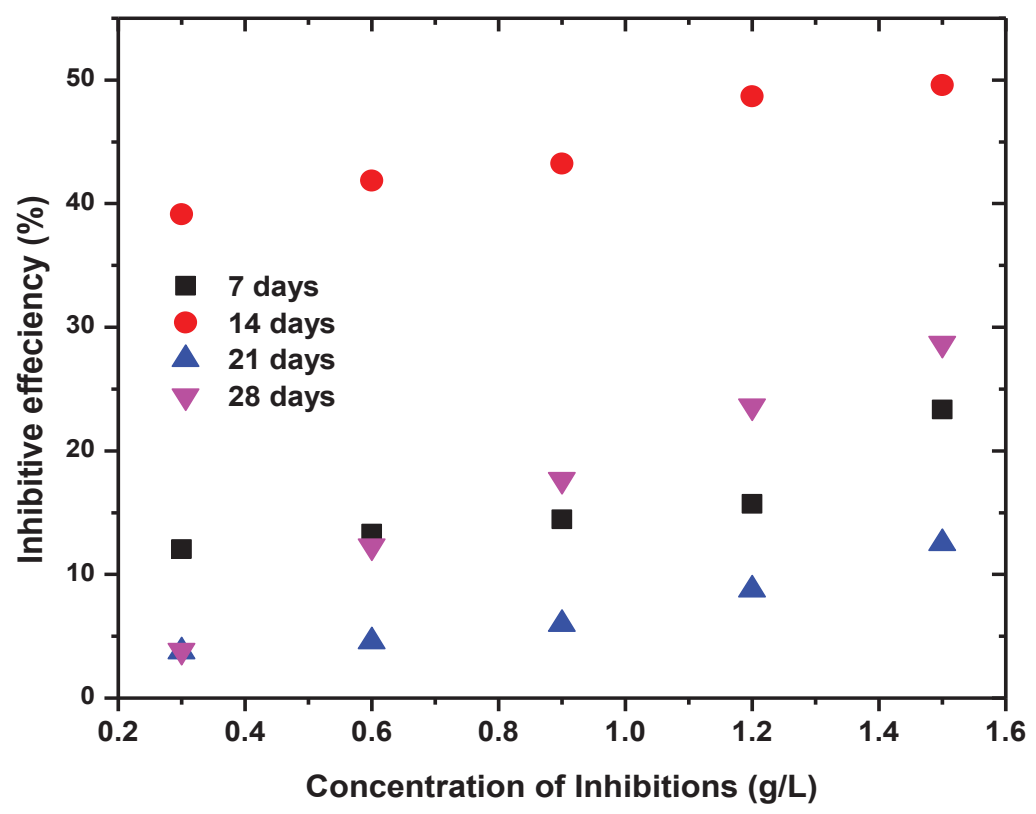

Fig. 6: Inhibitive efficiency under various concentrations of the Cascabela thevetia inhibitor. 


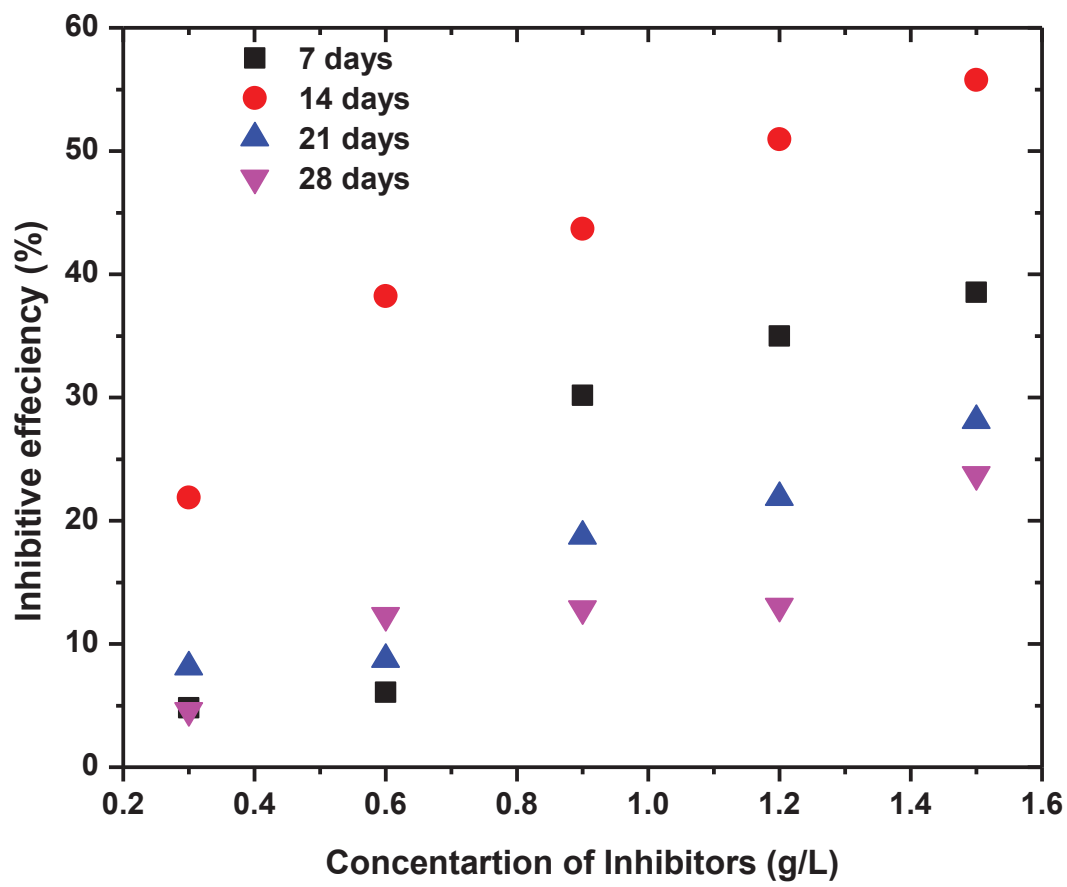

Fig. 7: Inhibitive efficiency under various concentrations of the Jatropha curcas inhibitor.

inhibitor concentration in the system. This could be instigated by phytochemical constituents' adsorption which is existing in the inhibitors (Table 2) that consequently cause a reduction in the penetrability of $\mathrm{H}_{2} \mathrm{SO}_{4}$ onto the surface of the metal. The least inhibitor inhibitive efficiency at $0.3 \mathrm{~g} / \mathrm{L}$ was found to be 21.9 and $39.2 \%$ for Jatropha curcas and Cascabela thevetia, respectively. After 14 days, without regard to the inhibitor concentration, the inhibitive efficiencies decline for both green inhibitors used. This study finds agreement with previous studies on corrosion inhibition as it was reported that mild steel corrosion rate in the corrosion system of nitric acid/Carica papaya decreased with increment in the concentration of the inhibiting leaf extracts while corrosion efficiency and surface coverage increased as inhibitors' concentration increase (Oki et al. 2015). More so, as the concentration of corrosion inhibitor increases, there is always a decrease in the weight loss of the metal in the corrosion system (Odusote \& Ajayi 2013, Oki et al. 2015, Salami et al. 2012). This was obtained from this study and such should be expected as stated by Oki et al. (2015) that the inhibiting species number will rise in proportion to the leaf extracts concentration in the system (Oki et al. 2015).

Gasometric studies: For both inhibitors, there was a linear decline in the hydrogen gas evolution rate as a result of time increment. This was, however, not as rapid as that of the blank (uninhibited) samples (Figs. 8 \& 9). Also, it was observed that the presence of the green inhibitors (Cascabela thevetia and Jatropha curcas) rapidly lowers the rate at which

Table 2: Phytochemical constituents of the inhibitors.

\begin{tabular}{|lcc|}
\hline Phytochemical constituent & Cascabela thevetia & Jatropha curcas \\
\hline Tanins & + & + \\
Saponins & + & + \\
Phenols & - & + \\
Flavonoids & + & + \\
Alkaloids & + & + \\
Terpenoids & - & - \\
Nicotine & & +
\end{tabular}




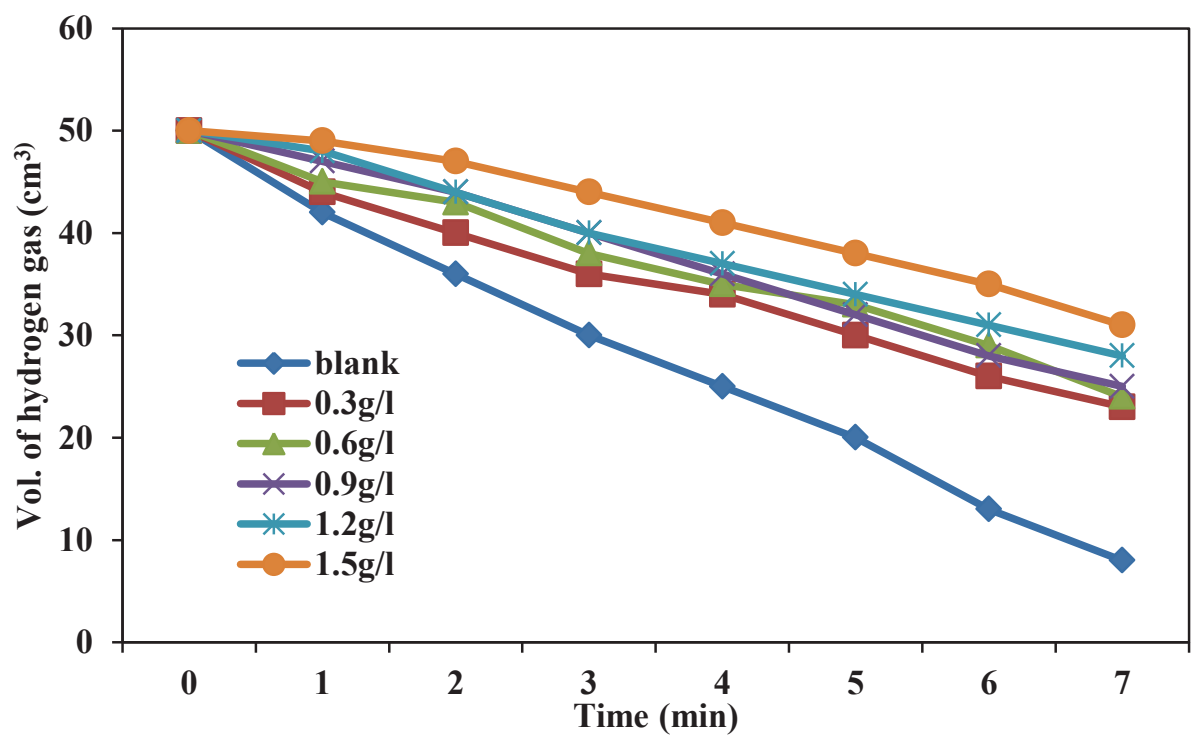

Fig. 8: Volume of hydrogen gas evolved against time (Cascabela thevetia).

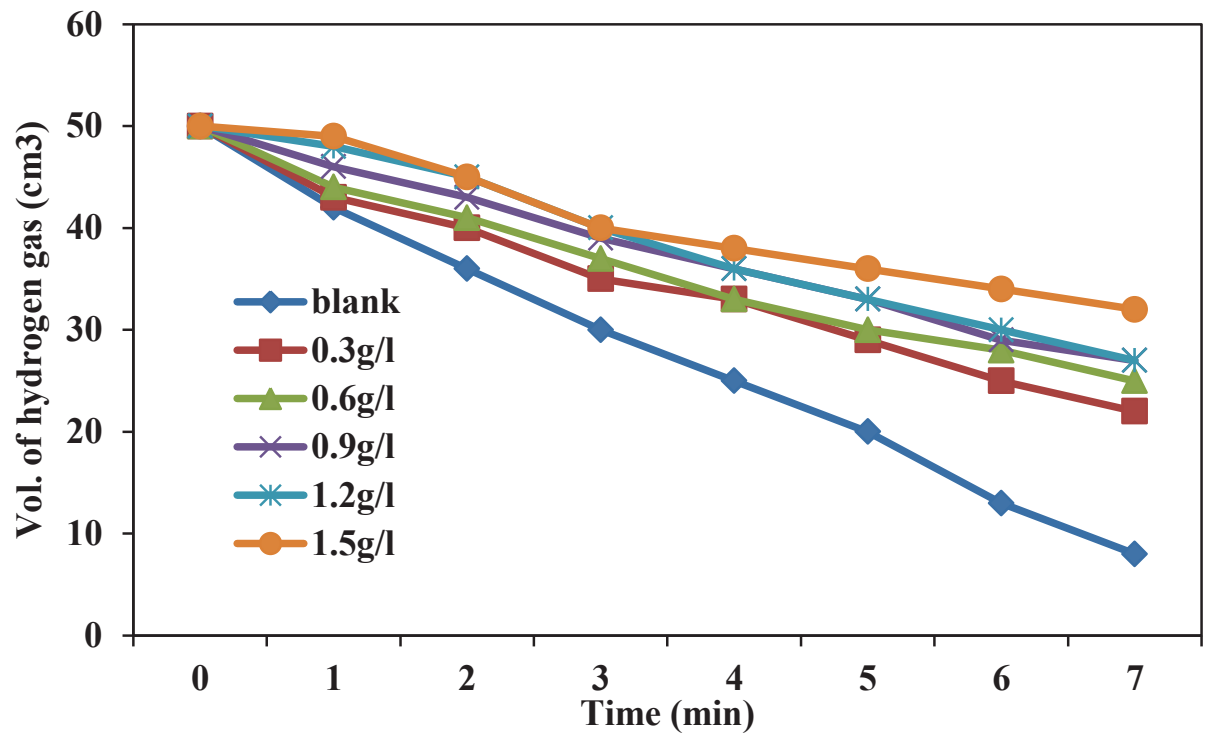

Fig. 9: Volume of hydrogen gas evolved against time (Jatropha curcas).

the hydrogen gas volume evolves. Also, it is observed that the gas evolution of the gas is inversely proportional to the inhibitors' concentration. This implies that the increment in the inhibitors' concentration results in a decrease in the evolution of the gas for both inhibitors. The same observation was reported by Oki et al. (2015) in which corrosion activities reduced with increment in leaf extract concentration of Carica papaya extracts in the corrosion system. The highest gas of evolution volumes at $0.3 \mathrm{~g} / \mathrm{L}$ concentration were 24 and $22 \mathrm{~cm}^{3}$ while the least gas evolution volumes at $1.5 \mathrm{~g} / \mathrm{L}$ concentration were 31 and $32 \mathrm{~cm}^{3}$ for both Cascabela thevetia and Jathropha curcas inhibitors, respectively at 7 minutes.

It was observed that there is an increment in the surface coverage for both green inhibitors as the concentration increases (Fig. 10). This could be the aftermath effect of the interactive reaction between the phytochemical constituents and $\mathrm{H}_{2} \mathrm{SO}_{4}$ which results in the declining nature of the acidic reaction rate on the mild steel coupons. This consequently 


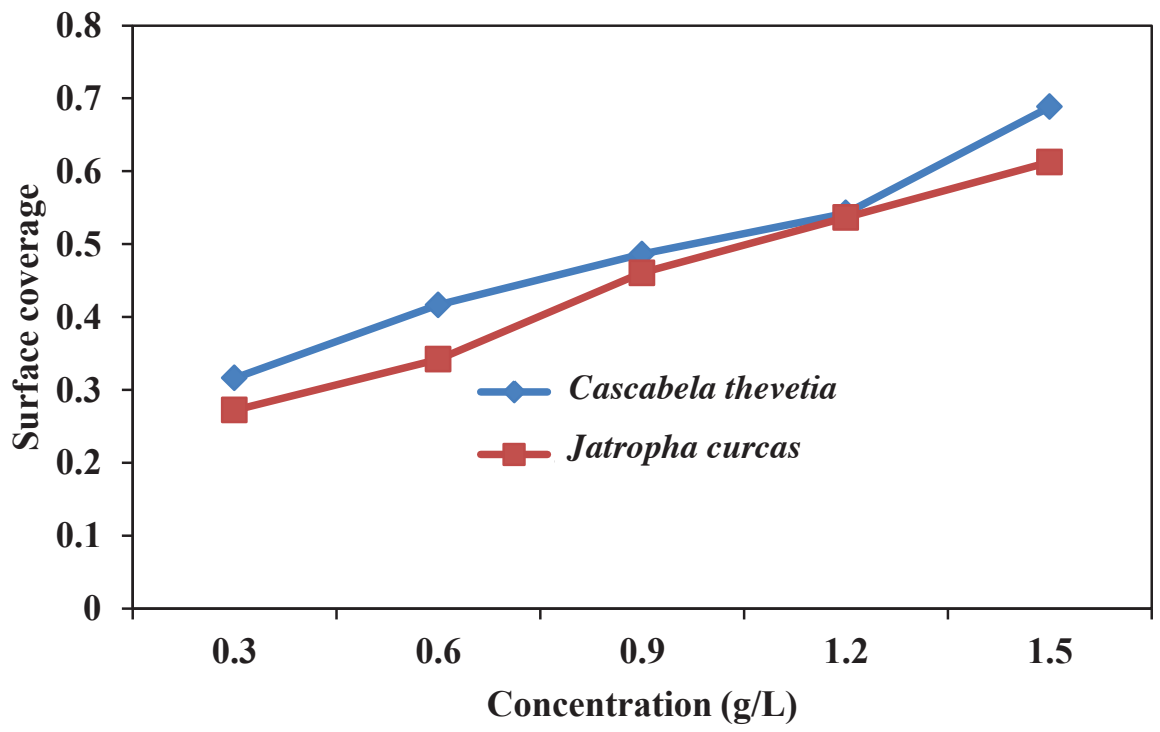

Fig. 10: Surface coverage against concentration for both inhibitors.

lowers the metal corrosion rate. The maximum surface coverage for the green inhibitors, Cascabela thevetia and Jatropha curcas, at $1.5 \mathrm{~g} / \mathrm{L}$ concentration were 0.68 and 0.61 , respectively and the lowest surface coverage at 0.3 $\mathrm{g} / \mathrm{L}$ concentration were 0.31 and 0.27 , respectively. This is an indication that Cascabela thevetia has a superior surface coverage for a short period of time compared to Jatropha curcas. The increment in time of surface coverage makes Jatropha curcas inhibit better and superiorly effective than Cascabela thevetia.
With increase in inhibitors' concentration, there is an increment in the inhibitive efficiency of both green inhibitors (Fig. 11). The highest inhibitive efficiency was at $1.5 \mathrm{~g} / \mathrm{L}$ concentration for both inhibitors and the values were $68.9 \%$ and $61.3 \%$ for Cascabela thevetia and Jatropha curcas, respectively. The lowest inhibitive efficiency was at $0.3 \mathrm{~g} / \mathrm{L}$ for both inhibitors and the values were 31.6 and $27.2 \%$ for Cascabela thevetia and Jatropha curcas, respectively.

This trend in corrosion inhibition efficiencies at various inhibitors concentrations indicate the phytochemical

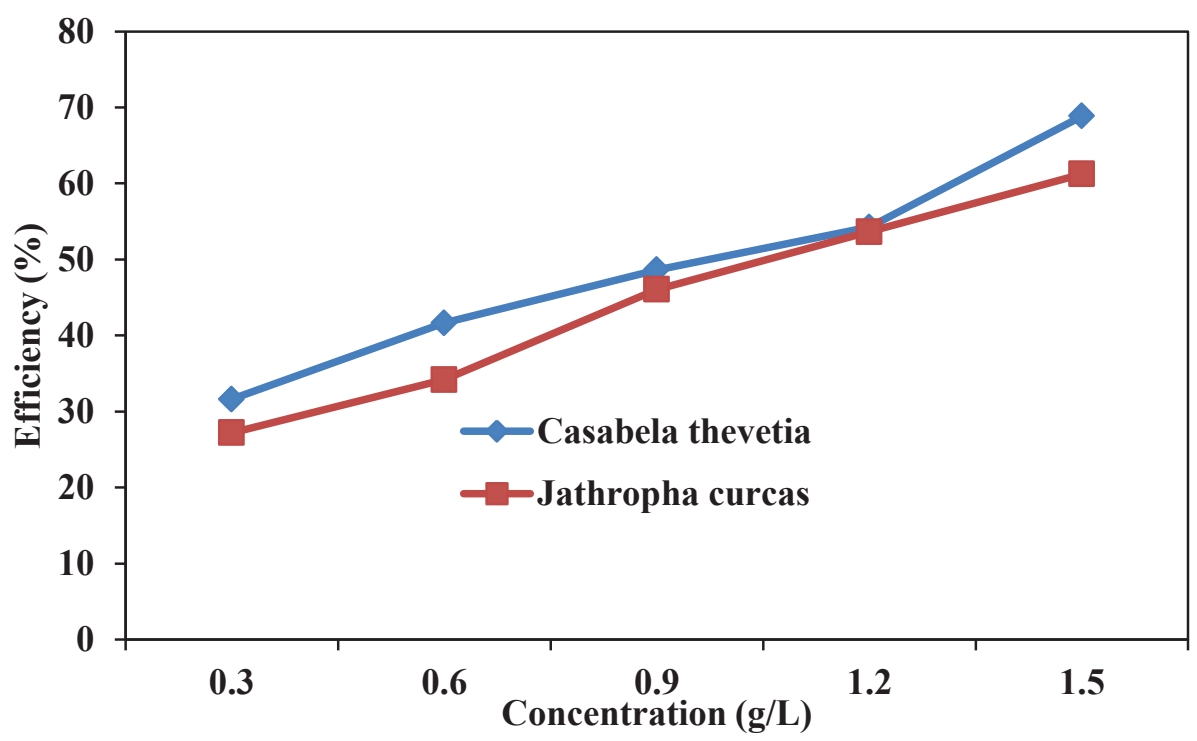

Fig. 11: Inhibitive efficiency against concentration for both inhibitors. 
constituents' chemisorption of the inhibitors on the metal surface. The mild steel coupon corrosion in $\mathrm{H}_{2} \mathrm{SO}_{4}$ solutions increase inhibitors' concentration which was attributed to the adsorption of the inhibitors' components on the metal surface.

Consequentially, during corrosion reactions, the anodic reaction rate is always equal to the cathodic reaction rate. This is so as a result of the utilization of all electrons released in the anodic half reaction by the cathodic half. Therefore, the gas evolution rate is a function and measure of the corrosion rate of the metallic specimen in the corrosion system (Oki et al. 2015).

\section{CONCLUSION}

Comparative examination of the influence of Cascabela thevetia and Jatropha curcas leaves extracts on mild steel was carried out in this study and the following were deduced.

1. The extracts have inhibitive efficiencies at $1.5 \mathrm{~g} / \mathrm{L}$ concentration (after 28 days) in $\mathrm{H}_{2} \mathrm{SO}_{4}$ to be 49.59 and $55.77 \%$ for Cascabela thevetia leaves and Jatropha curcas leaves, respectively.

2. As the concentration of the inhibitors (Cascabela thevetia and Jatropha curcas) increased in the $\mathrm{H}_{2} \mathrm{SO}_{4}$ medium, the weight loss, the corrosion rate and the hydrogen gas evolved decreased.

3. Cascabela thevetia had better surface coverage for a shorter period while Jatropha curcas had superior coverage with prolonged time. The inhibition property is best with Jatropha curcas.

4. The gas evolution is dependent on the inhibitors' concentration, therefore, increment in the inhibitors' concentration reduces gas evolution.

\section{REFERENCES}

Abiola, O.K., Oforka, N.C., Ebenso, E.E. and Nwinuka, N.M. 2007. Eco-friendly corrosion inhibitors: The inhibitive action of Delonix regia extract for the corrosion of aluminium in acidic media. Anti-Corros. Meth. Mat., 54(4): 219-224.

Ajayi, O.O., Joseph, O.O., Omotosho, O.A. and Olabowale, T.O. 2012. Rauvolfia vormitoria effect on the degradation of aluminium alloy in 2.5M hydrochloric acid solution, In: Proceeding of ICCEM: 21-29.

Al-Otaibi, M.S., Al-Mayouf, A.M., Khan M., Mousa, A.A., Al-Mazroa, S.A. and Alkhathlan, H.Z. 2012. Corrosion inhibitory action of some plant extracts on the corrosion of mild steel in acidic media. Arab. J. Chem., 7(3): 340-346

Ansari K.R., Yadav, D.K., Ebenso, E.E. and Quraishi, M.A. 2012. Novel and effective pyridyl substituted 1,2,4-triazole as corrosion inhibitor for mild steel in acidic solution. Int. J. Electrochem. Sci., 7: 4780 - 4799

Asmara, Y.P., Suraj, V., Sire6gar, J.P., Kurniawan, T., Bachtiar, D. and Mohamed, N.M.Z.N. 2017. Development of green vapour corrosion inhibitor. $4^{\text {th }}$ International Conference on Mechanical Engineering re- search. In: IOP Conference Series: Materials Science and Engineering, 257 (012089): 1-7.

Bradford, S. A. 1993. Corrosion Control, Van Nostrand Reinhold, New York: 1

Chowdhary, R., Jain, T., Rathoria, M. K. and Mathur, S. P. 2004. Corrosion inhibition of mild steel by acid extracts of Prosopis juliflora. Bullet. Electrochem., 20(2): 67-75.

Ebenso, E. E., Eddy, N. O. and Odiongeyi, A. O. 2008. Corrosion inhibitive properties and adsorption behaviour of ethanol extract for Piper guinensis as a green corrosion inhibitor for mild steel in $\mathrm{H}_{2} \mathrm{SO}_{4}$. Afr. J. Pure App. Chem., 2(11): 107-115.

Eddy, N. O. 2009. Ethanol extract of Phyllanthus amarus as a green inhibitor for the corrosion of mild steel in $\mathrm{H}_{2} \mathrm{SO}_{4}$. Portug. Electrochem. Acta, 29(5): 579-589.

El-Etre, A. Y. and El-Tantawy, Z. 2006. Inhibition of metallic corrosion using Ficus extract. Portug. Electrochim. Acta, 24(3): 347- 356.

El-Etre, A. Y., Abdallah, M. and El-Tantawy, Z. E. 2005. Corrosion inhibition of some metals using Lawsonia extract. Corros. Sci., 47(2): 385-395.

El-Etre, A. Y., Abdallah, M. and Z. E. El-Tantany. 2005. Corrosion inhibition of some metals using Lawsonia extract. Corrosion Science, 47: 385-395.

El-Etre, A.Y. 2006. Natural onion juice as inhibitor for zinc corrosion. Bullet. Electrochem., 22(2): 75-80.

Martinez, S. 2003. Inhibitory mechanism of Mimosa tannin using molecular modeling and substitutional adsorption isotherms. Mat. Chem. Phys., 77: 97-102.

Mshelia, A.D., Aji, I.S. and Yawas, D.S. 2017. Comparative analysis of Jatropha curcas and Neem leaves extracts as corrosion inhibitors on mild steel. Faculty of Engineering Seminar Series, 8: 106-113.

Odusote, J.K. and Ajayi, O.M. 2013. Corrosion inhibition of mild steel in acidic medium by Jatropha curcas leaves extract. J. Electrochem. Sci. Technol., 4(2): 81-87.

Oguzie, E. E. and Ebenso, E. E. 2006. Studies on the corrosion inhibiting effect of Congo red dye halide mixtures. Pigment \& Resin Technol., 35(1): $30-35$.

Oguzie, E. E. 2008. Corrosion inhibitive e ect and adsorption behaviour of Hibiscus sabdari a extract on mild steel in acidic media. Portug. Electrochim. Acta, 26: 303-314.

Okafor P.C., Ikpi, M.E., Uwah, I. E., Eneso, E.E., Ekpe, U.J. and Umoren, S.A. 2008. Inhibitory action of Phyllanthus amarus extracts on the corrosion of mild steel in acidic media. Corrosion Science, 50(8): 2310-2317.

Okafor, P. C., Ebenso, E. E. and Ekpe, U. J. 2010. Azadirachta indica extracts as corrosion inhibitor for mild steel in acid medium. Int. J. Electrochem. Sci., 5: 978-993.

Oki, M., Anawe, P. A. L. and Fasakin, J. 2015. Performance of mild steel in nitric acid/Carica papaya leaf extracts corrosion system. Asian J. Appl. Sci., 3(1): 110-116

Oki, M., Charles, E., Alaka, C. and Oki, T. K. 2011. Corrosion inhibition of mild steel in $\mathrm{HCl}$ by tannins from Rhizophora racemose. Mat. Sci. App., 2: 592-595.

Perez, N. 2004. Electrochemistry and Corrosion Science. Kluwer Academic Publishers, New York: 1.

Rani B.E.A. and Basu, B. B. J. 2012. Green inhibitors for corrosion protection of metals and alloys: An overview. Int. J. Corros., 2012: 1-15.

Rani, P. D. and Selvaraj, S. 2010. Inhibitive and adsorption properties of $P u$ nica granatum extract on brass in acid media. J. Phytology, 2(11): 58-64.

Salami, L., Wewe, T. O. Y., Akinyemi, O. P. and Patinvoh, R. J. 2012. A study of the corrosion inhibitor of mild steel in sulphuric acid using Musa sapientium peels extract. Glob. Eng. Technol. Rev., 2(12): 1- 6.

Singh A., Ebenso, E.E. and Quraishi, M. A. 2012. Corrosion inhibition of carbon steel in $\mathrm{HCl}$ solution by some plant extracts. Int. J. Corros., 2012: 1-20. 
Syed, S. 2006. Atmospheric corrosion of materials. Emir. J. Eng. Res., 11(1): 1-24.

Taghavikish, M., Dutta, N.K, and Choudhury, N.R. 2017. Emerging corrosion inhibitors for interfacial coating. Coatings, 7(12): 217-244.
Umoren S.A., Obot, I.B., Ebenso, E.E., Okafor, P.C., Ogbobe, O. and Ogusie, E.E. 2006. Gum Arabic as a potential corrosion inhibitor for aluminium in alkaline medium and its adsorption characteristics, anti-corros. Methods and Materials, 53(5): 277-282. 